Article

\title{
Plant-Inspired Layer-by-Layer Self-Assembly of Super-Hydrophobic Coating for Oil Spill Cleanup
}

\author{
Liping Ding ${ }^{1, \dagger}$, Yanqing Wang ${ }^{1,2, *,+}$, Jinxin Xiong ${ }^{1}$, Huiying Lu ${ }^{1}$, Mingjian Zeng ${ }^{1}$, Peng Zhu ${ }^{1, *}$ \\ and Haiyan $\mathrm{Ma}^{1, *}$ \\ 1 School of Chemistry and Chemical Engineering, Nantong University, Nantong 226007, China; \\ dingliping@ntu.edu.cn (L.D.); a1835948675@163.com (J.X.); luhuiying722@163.com (H.L.); \\ z1743552875@163.com (M.Z.) \\ 2 Department of Materials Science \& Engineering, National University of Singapore, \\ Singapore 117575, Singapore \\ * Correspondence: msewyaq@nus.edu.sg (Y.W.); zhupeng@tehssun.com (P.Z.); mhyan2528@163.com (H.M.) \\ + Liping Ding and Yanqing Wang contributed equally to this work.
}

Received: 24 August 2019; Accepted: 21 November 2019; Published: 10 December 2019

check for updates

\begin{abstract}
A versatile, facile, energy-saving, low-cost and plant-inspired self-assembly strategy was used to prepare super-hydrophobic coating in this study. Concretely, an appealing super-hydrophobicity surface was obtained by designing a molecular building block phytic acid (PA)-Fe (III) complex to anchor the substrate and hydrophobic thiol groups (HT). The facile and green modification method can be applied to variety of substrates. The as-prepared PA-Fe (III)-HT coated melamine composite sponge possesses both super-hydrophobic and superlipophilicity property. Moreover, it displays superior efficiency to separate the oil-water mixture and splendid oil spill cleanup.
\end{abstract}

Keywords: plant-inspired chemistry; self-assembly strategy; surface modification; super-hydrophobicity

\section{Introduction}

The petroleum industry is the basic industry of the national economy. The machinery, electricity, petrochemical, automobile, architecture, and other traditional industries, and even the increasingly important electronic industry and the development of many high-tech industries, all rely on oil resources [1,2]. Oil plays an irreplaceable role in economic development, but it also brings serious environmental pollution problems due to accidents and improper reprocessing in the actual production process [3,4]. The direct combustion method is usually adopted to remove the oil pollutants in the follow-up treatment of the offshore oil spill [5,6]. However, direct burning of oil will not only cause a waste of resources but also pollute the air. If the leaked oil can be separated from seawater and recycled, the problems of resource waste and environmental pollution can be solved well. Based on the insoluble nature of oil and water, the researchers have designed many hydrophobic materials for oil-water separation and recovery in recent years [7-9]. Particle materials [10-12] such as $\mathrm{TiO}_{2}$ and carbon spheres, two-dimensional materials such as planar membranes, nanofibers, and hollow fibers [13-16], and three-dimensional materials [17-20] such as sponges and foam have been used in oil-water separation experiments. The particle materials with a large surface area can quickly absorb a thin layer oil phase on the water surface, but their low absorption capacity and difficult collection limit their application in the oil-water separation field. After the surface modification of the two-dimensional materials, the hydrophobicity of the film surface can be obtained, and the oil-water mixture can be separated continuously under the action of gravity. Unfortunately, the two-dimensional film materials must be in a specific device in order to play its role and is not suitable for the treatment of large-scale oil leakage at sea. Herein, nowadays, oil-water separation materials are mainly focused 
on three-dimensional porous hydrophobic materials [21-23]. Three-dimensional porous hydrophobic materials have a large amount of storage space, which can directly absorb the leaked oil on the sea surface, and its bulk structure is easy to transport after the completion of oil absorption process. On the premise of satisfying the good oil absorption function, 'fast, simple and easy to release the absorbed oil from the material' becomes the criterion for the selection of suitable three-dimensional materials [24]. Polymer-based three-dimensional porous materials (such as sponge, foam, and aerogel) are considered to be ideal materials for oil leakage treatment because of their multi-layer network structure, absorption capacity, long penetration channel, and adjustable pore structure. In particular, the polymer has excellent flexibility, which makes it have high elasticity. The absorption oil is discharged by compression, which simplifies the separation process [25]. For a more efficient, cheaper, and readily scalable remediation solution, modified commercially available polymer sponges/foams have recently arisen as a suitable supporting body for oil spills' remediation [26]. Melamine sponge not only has the characteristics of network interworking structure, high porosity, large specific surface area and low density, but also has good thermal stability and compressibility [27-30]. After hydrophobic modification, the sponge can not only absorb the oil phase but also release the absorbed oil phase by simple extrusion, which greatly reduces the recovery cost of the oil phase. According to the theory of Wenzel and the Cassie-Baxter model, the hydrophobic properties of the material surface are determined by the chemical properties and the roughness of the material surface [31,32]. Silicon/fluorine materials are common low surface energy material, which has excellent properties such as weather resistance, refractory, corrosion resistance, and oxidation stability [18,33-35]. However, silicon/fluorine modified coatings have the problems of high price and a complex preparation process, which limits its large-scale application. Therefore, it is highly desirable to develop a simple and economical method to fabricate melamine sponge with super-hydrophobic qualities for large-scale offshore oil spills. With the scarcity of oil resources, there is a deterioration of the environment and the aggravation of a greenhouse effect. The manufacturing method of the green economy is particularly important. Getting effective ingredients from common animals and plants is a new inspiration for solving these problems. In recent years, inspired by the extraction of raw materials from animals and plants, more and more studies on dopamine [36], levodopa [16], tannic acid [37], gallic acid [38], and lignin [39] have been reported. In this paper, a versatile, facile, energy-saving, low-cost but efficient plant-inspired strategy was developed to prepare the super-hydrophobic melamine sponge (Figure 1). This strategy employs a metal-organic coordination-enabled layer-by-layer (LbL) self-sssembly method to prepare super-hydrophobic coating. Metal-organic coordination structures' materials contain reticular metal centers and organic linkers. The above two constituents can bind with each other via metal-ligand coordination interaction [40]. Metal-organic coordination endows not only a peculiar combination of hardness and extensibility, but also a covalent-like stability [41]. It would be highly desirable that these properties are introduced into the LbL self-assembly process to acquire the super-hydrophobic coating by a facile and controllable way [42]. Our strategy offers several distinct advantages, including the following: (i) the super-hydrophobic modification surface can be fabricated at room temperature without any harsh preparation condition. (ii) Our method is conducted by using the chelate reaction between PA and Fe (III) and is suitable for a wide variety of substrates. (iii) Plant-derived PA, commercial $\mathrm{FeCl}_{3}$, and hexadecyl thiol (HT) are low-cost, so this fabrication technology shows good industrial application potential. 


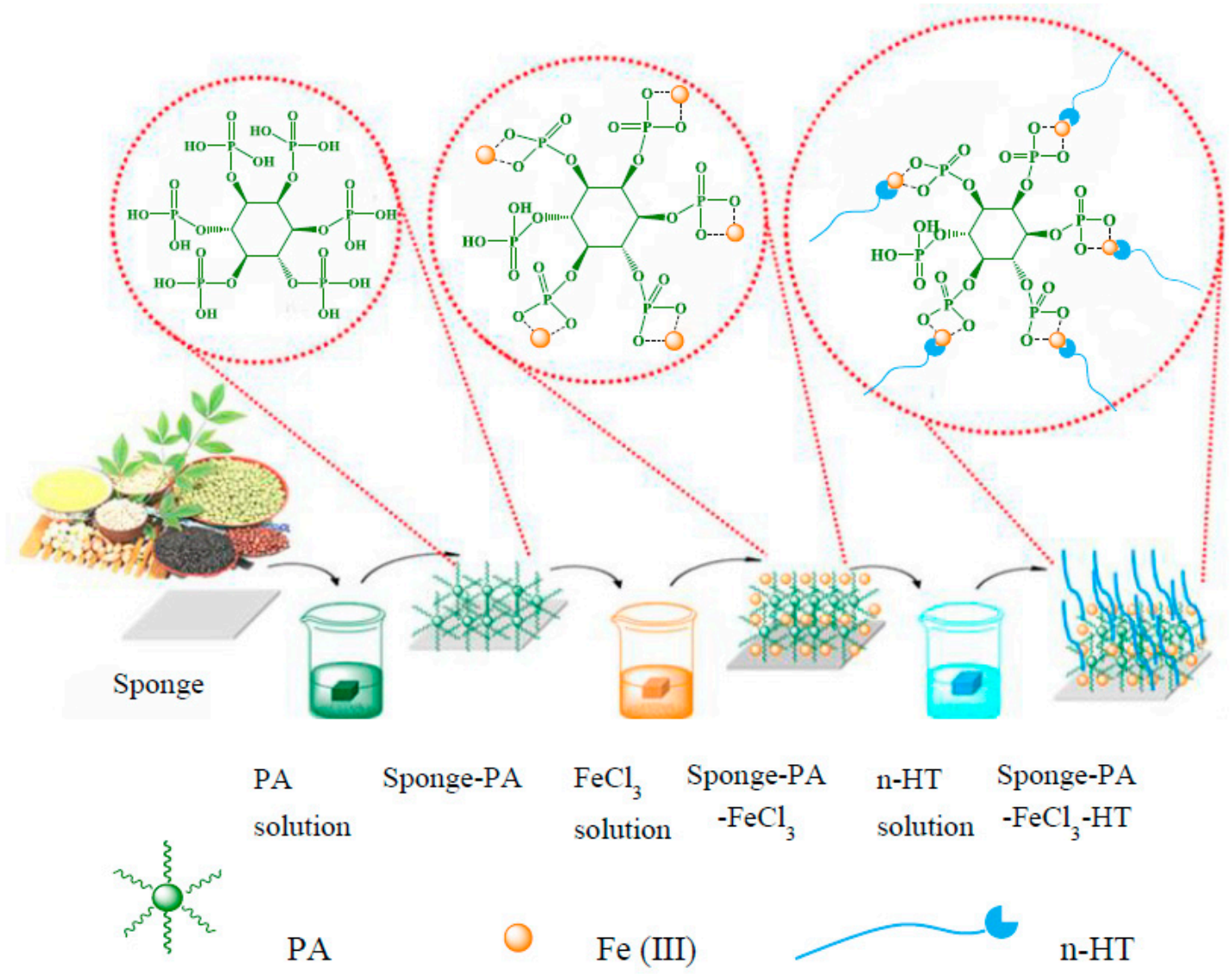

Figure 1. Schematic description of fabricating super-hydrophobic coating on sponges.

\section{Experimental}

\subsection{Materials}

Melamine sponge, polyurethane sponge, and non-woven fabric were provided from Hart New Materials Research Institute Co., Ltd. (Wuxi, China). Hexadecyl thiol (>99\%), $\mathrm{FeCl}_{3} 6 \mathrm{H}_{2} \mathrm{O}$, methyl blue, oil red, phytic acid (50 wt \% in water), sodium chloride, sodium hydroxide, ethanol (99.5\%), toluene $(>99.8 \%)$, petroleum ether $(>99 \%)$, dichloroethane $(>99 \%)$, and hydrochloric acid $(32 \%)$ were purchased from Sigma-Aldrich (Shanghai, China). Gasoline, diesel oil, heat-conductive silicone oil and corn oil were purchased from a local store. All chemicals were used as received without further purification.

\subsection{Layer by Layer Self-Assembly Super-Hydrophobic Modification of Various Highly Hydrophilic Polymer Materials}

The pristine melamine sponge (size of $3 \mathrm{~cm} \times 3 \mathrm{~cm} \times 2 \mathrm{~cm}$, porosity $>99 \%$ ), polyurethane sponge (size of $3 \mathrm{~cm} \times 3 \mathrm{~cm} \times 2 \mathrm{~cm}$, porosity $>95 \%$ ) and non-woven fabric (size of $3 \mathrm{~cm} \times 2 \mathrm{~cm}$ ) were washed sequentially with distilled water and ethanol under ultrasonic conditions for about $30 \mathrm{~min}$ and then dried in an oven at $60^{\circ} \mathrm{C}$. The dry substrates were immersed in the PA solution $(5 \mathrm{~g} / \mathrm{L}, 50 \mathrm{~mL})$ for $2 \mathrm{~min}$ first, and then the excess solution was squeezed to remove unabsorbed PA. After that, the substrates were immersed into $50 \mathrm{~mL}$ of a $0.1 \mathrm{~mol} / \mathrm{L}$ of $\mathrm{FeCl}_{3} \cdot 6 \mathrm{H}_{2} \mathrm{O}$ solution for another $1 \mathrm{~min}$ and then the excess solution was squeezed to remove the excess $\mathrm{FeCl}_{3} \cdot 6 \mathrm{H}_{2} \mathrm{O}$ solution. So far, a self-assembly layer has been completed. Similarly, the multiple-cycle assembly was achieved by repeating cycles of alternately dipping the substrates into the PA aqueous solution and the $\mathrm{FeCl}_{3} \cdot 6 \mathrm{H}_{2} \mathrm{O}$ solution. There are no washing steps between different cycles. In this experiment, for melamine sponge modification, a maximum of 10 cyclic experiments have been done. After completing the multiple-cycle assembly, the $\mathrm{PA}-\mathrm{FeCl}_{3}$ coated substrates were rinsed with deionized water and dried at $60{ }^{\circ} \mathrm{C}$. The $\mathrm{PA}-\mathrm{FeCl}_{3}-\mathrm{HT}$ coated 
substrates were achieved by immersing the dried substrates into an ethanol solution containing $1 \mathrm{wt} \%$ $\mathrm{HT}$ for $24 \mathrm{~h}$, then rinsed with ethanol and deionized water in turn and finally dried at $80^{\circ} \mathrm{C}$ for $4 \mathrm{~h}$.

\subsection{Characterizations and Measurements}

\subsubsection{Structure and Morphology Characterizations}

Infrared spectra of the melamine sponge, polyurethane sponge and non-woven fabric were performed by Fourier Transform Infrared spectroscopy (FT-IR) (Bruker, Karlsruhe, Germany) under the attenuated total reflection (ATR) mode. Surface morphologies of the pristine and modified melamine sponge, polyurethane sponge and non-woven fabric were characterized by scanning electron microscopy (SEM, ZEISS, Evo-10, Jena, Germany). The element mapping texts of the modified melamine sponge were characterized by scanning electron microscopy (SEM, ZEISS, Sigma-300, Jena, Germany) and energy-dispersive spectroscopy (EDX). The contact angle tests of the pristine and modified polymer materials were measured by a contact angle measuring system (Dataphysics, OCA20, Stuttgart, Germany).

\subsubsection{Oil/Water Separation Experiments}

The prepared hydrophobic melamine sponge was immersed in various oil phases or organic solvents and then quickly taken out. The oil absorption capacity was determined according to the mass change of the material before and after absorption. It was calculated using Equation (1):

$$
\mathrm{AC}=\frac{\mathrm{W}_{\mathrm{a}}-\mathrm{W}_{\mathrm{b}}}{\mathrm{W}_{\mathrm{b}}}
$$

$W_{\mathrm{b}}$ and $W_{\mathrm{a}}$ are the weight of melamine sponge before and after oil absorption, respectively. The recycling ability of the hydrophobic material is reflected according to the repeated absorption extrusion test. Firstly, the material is saturated and absorbed, and then the absorbed oil phase is released by external force extrusion. The weight of each absorption extrusion cycle was taken to determine the recycling absorption capacity of the material.

\section{Results and Discussion}

Figure 2 describes the structural changes of modified melamine sponge by layer-by-layer self-assembly strategy. Figure $2 \mathrm{a}, \mathrm{b}$ are the FT-IR spectra of modified melamine sponge. Figure $2 \mathrm{~b}$ is $\mathrm{a}$ local magnification graph of Figure 2a. After being coated with PA layer, two characteristic peaks of PA at $1145 \mathrm{~cm}^{-1}(\mathrm{P}=\mathrm{O})$ and $3328 \mathrm{~cm}^{-1}(-\mathrm{OH})$ are observed (Figure 2a red curve). The absorption intensity of $\mathrm{P}=\mathrm{O}$ groups becomes significantly weak after being cross-linked with $\mathrm{Fe}$ (III) ion, and -OH peak at $3328 \mathrm{~cm}^{-1}$ becomes a little stronger (Figure 2a,b green curve). After hydrophobic modification, the characteristic absorption peaks of HT at $1471 \mathrm{~cm}^{-1}(-\mathrm{CS}-), 2848 \mathrm{~cm}^{-1}\left(-\mathrm{CH}_{2}-\right)$ and $2925 \mathrm{~cm}^{-1}$ $\left(-\mathrm{CH}_{3}\right)$ appear (Figure 2a,b blue curve) [43]. These results confirm the successful incorporation of the hydrophobic function HT on the surface of the sponge. EDX mapping images (Figure S1: The initial image before mapping) of the PA-Fe (III)-HT-sponge further reveal the existence and uniform distribution of S, P, and Fe elements on the sponge surface (Figure 2c). Notably, these FT-IR and EDX figures only demonstrate the introduction of PA-Fe (III)-HT, and X-ray photoelectron spectroscopy (XPS) measurement was employed to provide more information about the interactions between the PA-Fe (III)-HT layers. The survey scan spectra and the chemical composition of the modified melamine sponge are presented in Figure S2. The existence of the absorption peaks at $133.6 \mathrm{eV}$ (3.36\%) (P2p), $165.5 \mathrm{eV}(1.48 \%)(\mathrm{S} 2 \mathrm{p})$, and $711.2 \mathrm{eV}(2.42 \%)(\mathrm{Fe} 2 \mathrm{p})$ of the PA-Fe (III)-HT-sponge demonstrates that the phosphate groups and long-chain alkyl thiol were successfully introduced into the modified layer and further cross-linked with Fe (III) ion. The O, S, and Fe core-level spectra of modified melamine sponge are shown in Figure 2d-f. As shown in Figure 2d, the O1s spectrum of the modified melamine sponges could be divided into $\mathrm{P}=\mathrm{O}(532.8 \mathrm{eV}),-\mathrm{P}-\mathrm{O}-\mathrm{H}(531.9 \mathrm{eV}),-\mathrm{P}-\mathrm{O}-\mathrm{C}-(531.5 \mathrm{eV})$, and $-\mathrm{P}-\mathrm{O}-\mathrm{Fe}-$ 
(530.9 eV). In Figure 2e, the S2p core-level spectrum (167.6 eV and $163.7 \mathrm{eV})$ represents -S-Fe and $-\mathrm{S}-\mathrm{C}$ absorption peaks, respectively. The Fe2p core-level spectrum (Figure 2f) is divided into two characteristic functional groups $-\mathrm{Fe}-\mathrm{O}$ and $-\mathrm{Fe}-\mathrm{S}$, respectively. To ensure the complete coverage of the original substrate surface and obtain a well-designed surface morphology with suitable micro/nano hierarchical roughness, the sponge was dipped into modification solutions several times. Figure $2 \mathrm{~g}$ is the contact angle of multiple-cycle assembly of modified melamine sponge (repeat cycles of alternately dipping the substrates into the PA aqueous solution and the $\mathrm{FeCl}_{3} \cdot 6 \mathrm{H}_{2} \mathrm{O}$ solution), the hydrophobicity of the modified sponge with nine cycles has the best hydrophobicity. The reason may be that HT needs to compete with PA to coordinate with ferric iron. Therefore, the super-hydrophobic property of the coating can be controlled by changing the concentration of iron ions (layer number of assembly) participating in the reaction. Based on the proper multiple-cycle assembly of PA-Fe (III) coating (nine cycles), the sponge was further modified by thiol-terminated, showing super-hydrophobicity.

The layer-by-layer assembly process can be further explained by Figure 3. PA contains six phosphonic acid groups that can be used as an organic ligand to bind well versatile substrates, including quartz, silicon, glass, $\mathrm{Al}$, stainless steel, polycarbonate, etc. [44]. In this paper, when the melamine sponge was first immersed in PA solution, the PA molecules could be absorbed and immobilized on the sponge substrate by covalent and/or non-covalent bonding by utilizing hydroxyl groups from phosphate group and the $-\mathrm{NH}_{2}$ group of the sponge surface. As the sponge was subsequently immersed into the Fe (III) solution, the PA-Fe (III) complexes aggregations would be further formed on the substrate to provide the appropriate surface topography and roughness for constructing super-hydrophobic surfaces (Figure S3). As is well-known, the wetting behavior of a surface is mainly related to both its surface topography and chemical composition. Therefore, the sponge was further modified with thiol-terminated molecules through the metal-thiol coordination, grafting the hydrophobic long-chain onto the PA-Fe (III) coating surface to achieve the hydrophobic modification of the substrate.
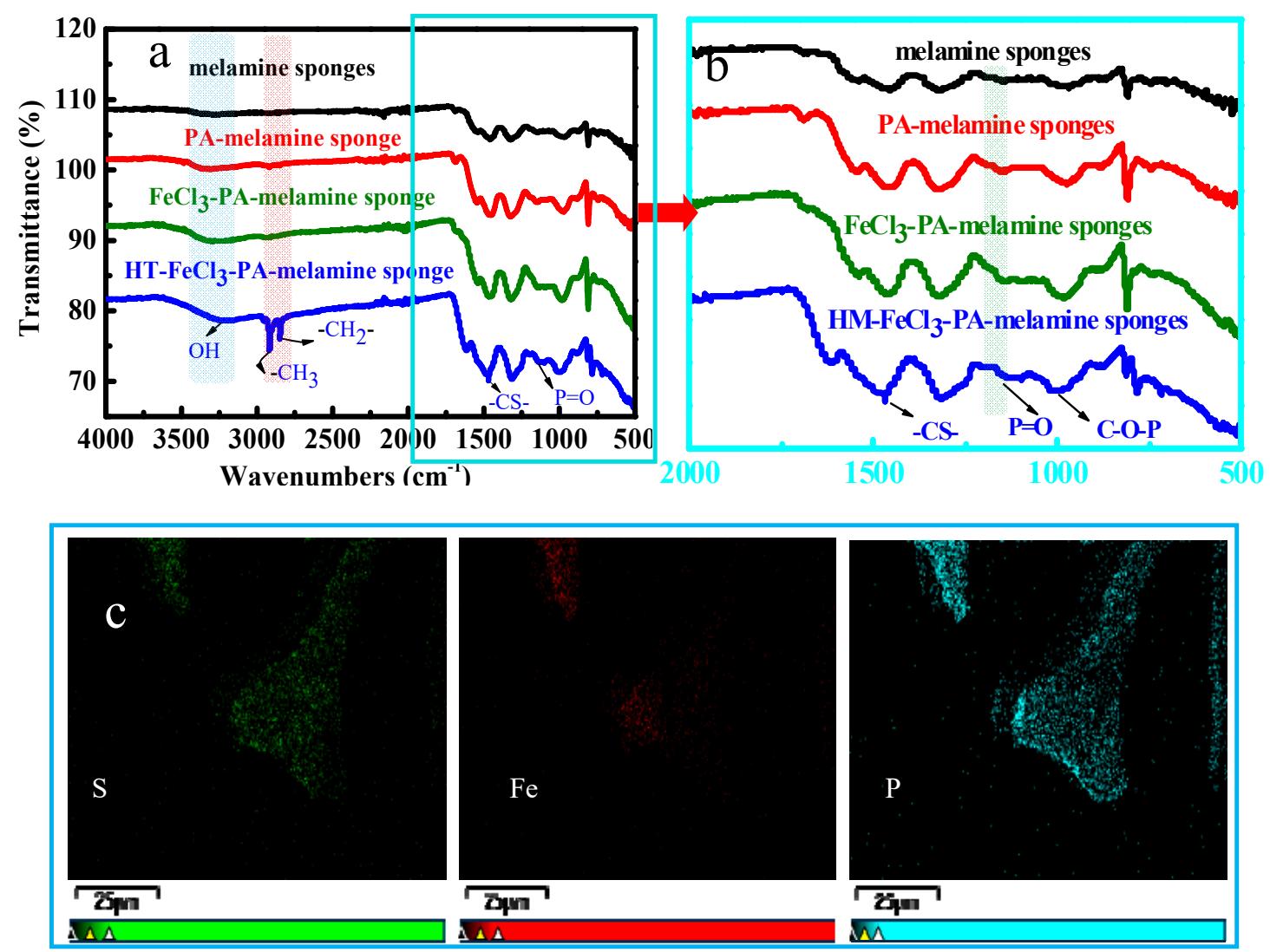

Figure 2. Cont. 

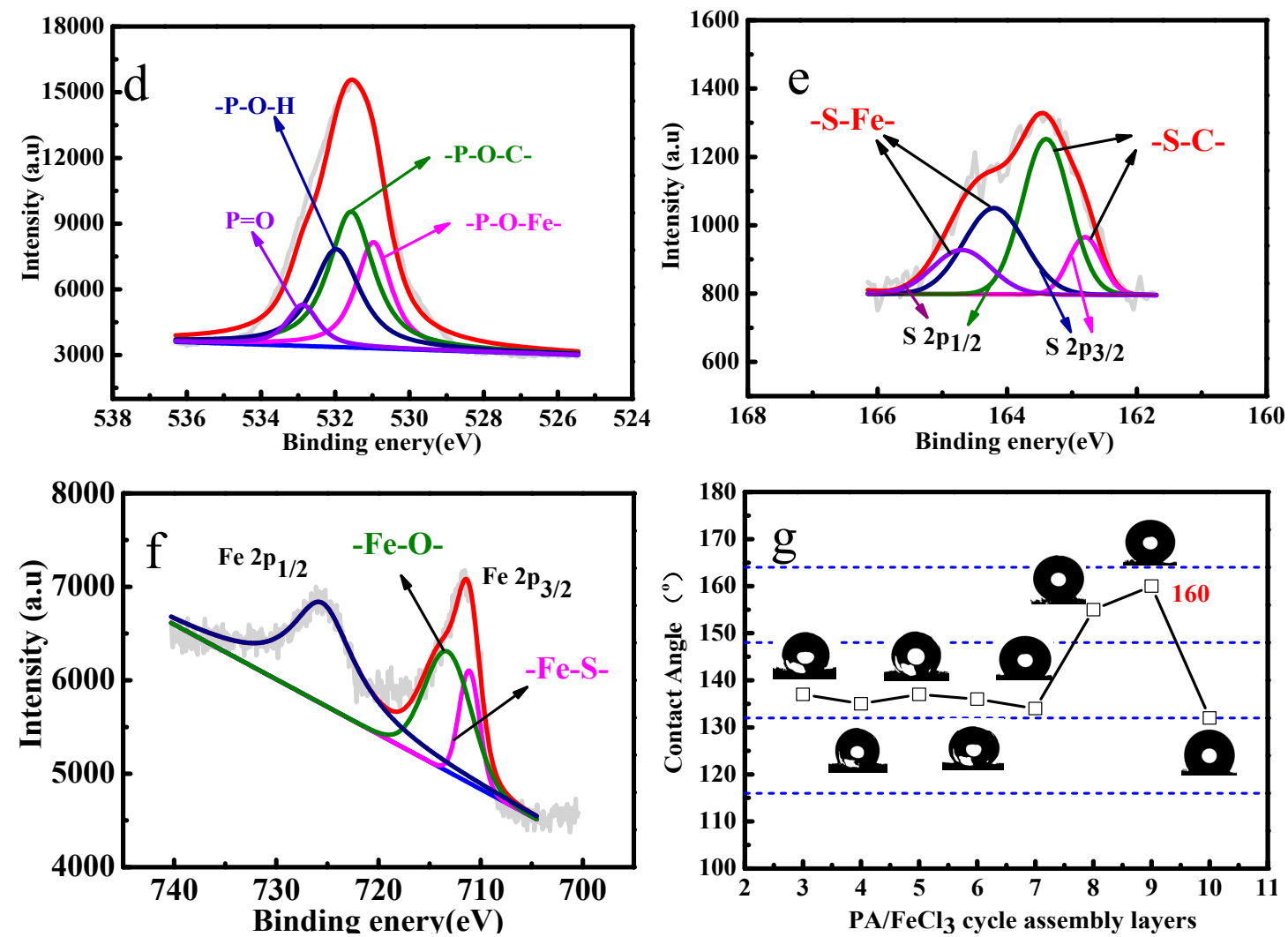

Figure 2. The FT-IR spectra (a,b), EDX map (c), O1s (d), S2p (e), and Fe2p (f) are level spectra of the PA-Fe (III)-HT-sponge, the contact angle of multiple-cycle assembly of modified melamine sponge (g).

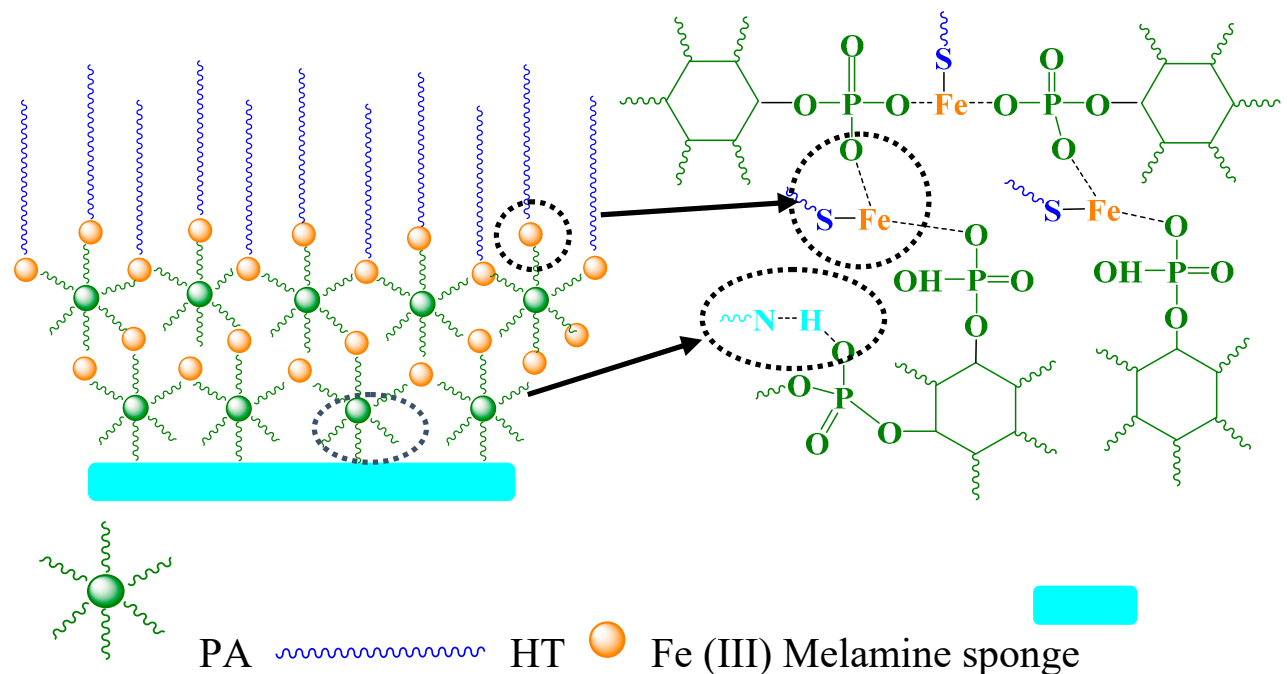

Figure 3. Chemical binding mechanism in the layer-by-layer assembly process.

Figure 4 shows the evolutive images in the surface morphology of modified substrate by the scanning electron microscopy (SEM) at different magnifications. For the pristine melamine sponge without PA-Fe (III)-HT treatment, it is clearly seen that the sponge is smooth and flat (Figure 4a). There is no micro/nano rough structure on the surface. However, for the melamine sponge after PA-Fe (III)-HT treatment, the SEM image displays that the sponge surface possesses randomly rough structures at the micro-nanometer scale (Figure 4d). Not only melamine sponge, but also the non-woven fabric (Figure $4 \mathrm{~b}, \mathrm{e}$ ) and polyurethane sponge (Figure $4 \mathrm{c}, \mathrm{f}$ ) were also fabricated successfully using this facile method, and their morphologies also present similar changes. SEM results demonstrate 
that the PA-Fe (III)-HT treatment results in the formation of micro/nanoscale hierarchical structures on the sponge surface, and it is very important for the final super-hydrophobicity. Figure $4 \mathrm{~g}-1$ are comparative pictures of hydrophilicity substrate before and after PA-Fe (III)-HT treatment. As shown in the figure, the pristine superhydrophilic melamine sponge (Figure 4g), non-woven fabric (Figure 4h) and hydrophilic polyurethane sponge (Figure 4i) become super-hydrophobic (Figure 4j-1) after being coated with PA-Fe (III) aggregations, followed by HT modification. Water droplets retain a spherical shape on the surfaces of the treated porous materials and all the water contact angles (WCAs) of samples are more than $150^{\circ}$.
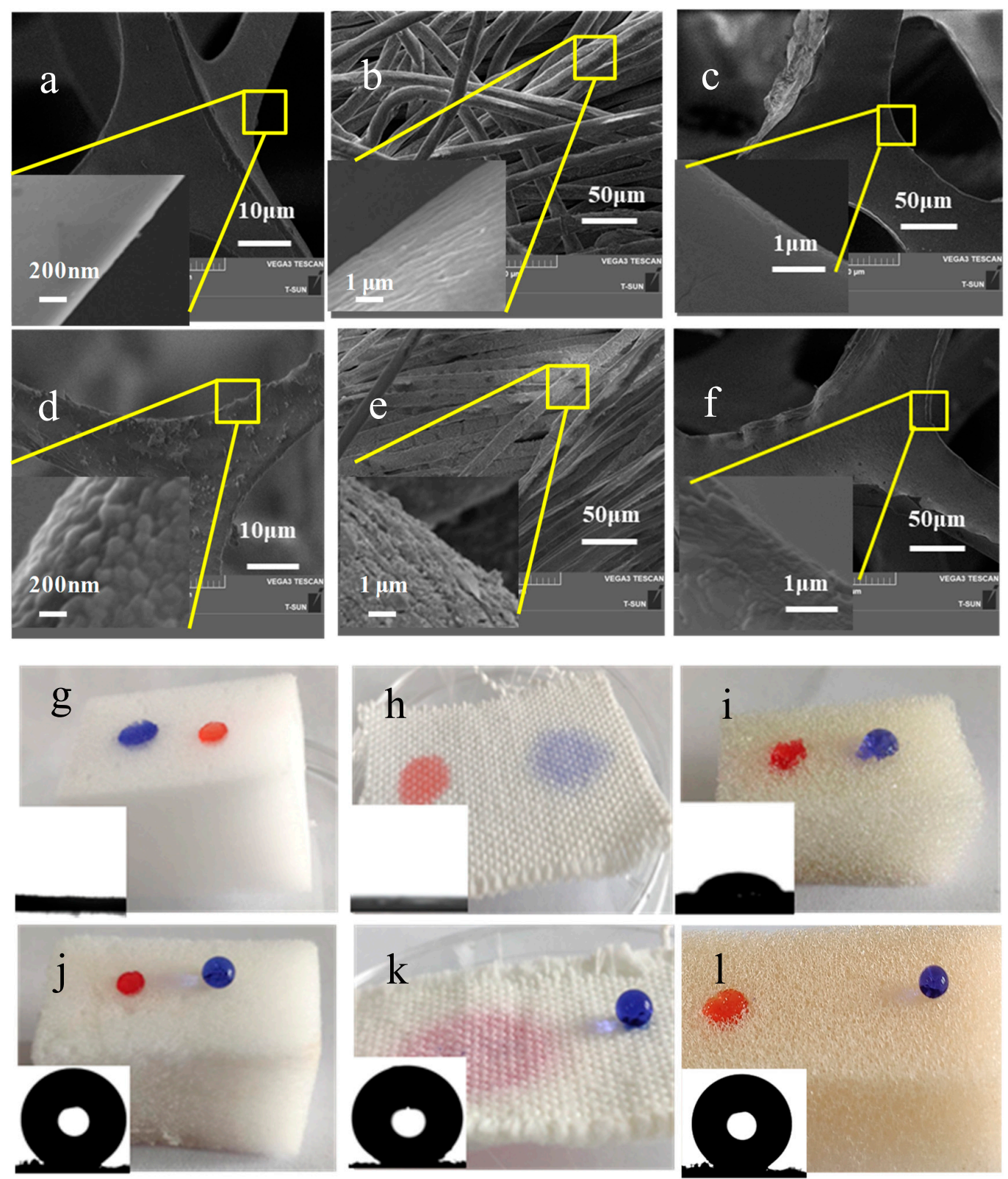

Figure 4. SEM images (a-f) and digital photos $(\mathbf{g}-\mathbf{l})$ of melamine sponge $(\mathbf{a}, \mathbf{d}, \mathbf{g}, \mathbf{j})$, polyurethane sponge $(\mathbf{b}, \mathbf{e}, \mathbf{h}, \mathbf{k})$ and non-woven fabric $(\mathbf{c}, \mathbf{f}, \mathbf{i}, \mathbf{l})$ before and after PA-Fe (III)-HT treatment.

To further investigate the hydrophobic properties and oil absorption ability of the coatings, a series of experiments were carried out. As shown in Figure $5 \mathrm{a}-\mathrm{c}$, the water droplets can be quickly rolled from the surface of the modified melamine sponge without leaving any marks (see Movie S1). Figure 5d shows that the pristine melamine sponge sinks to the bottom of the beaker while the modified melamine 
sponge floats on the water surface. Figure 5e indicates that it can be clearly seen that water cannot infiltrate the surface of the modified melamine sponge; on the contrary, water can completely infiltrate the internal unmodified melamine sponge. The reason is that the modified melamine sponge has the micro-nano-scale structure and the hydrophobic chemical property, and the as-prepared sample surface repels the water drops. As shown in Figure $5 \mathrm{f}-\mathrm{h}$, when the modified melamine sponge makes contact with the oil droplets that are submerged in water, it completely absorbs the droplet in an instant (see Movie S2). In addition, the modified melamine sponge has absorption properties for different kinds of oil besides dichloromethane (Figure 5i). Figure $5 i$ also intuitively shows the lipophilic and hydrophobic characteristics of the modified sponge. Moreover, the modified melamine sponge could efficiently separate dichloromethane/water mixture solely under gravity (Figure 5j, see Movie S3).
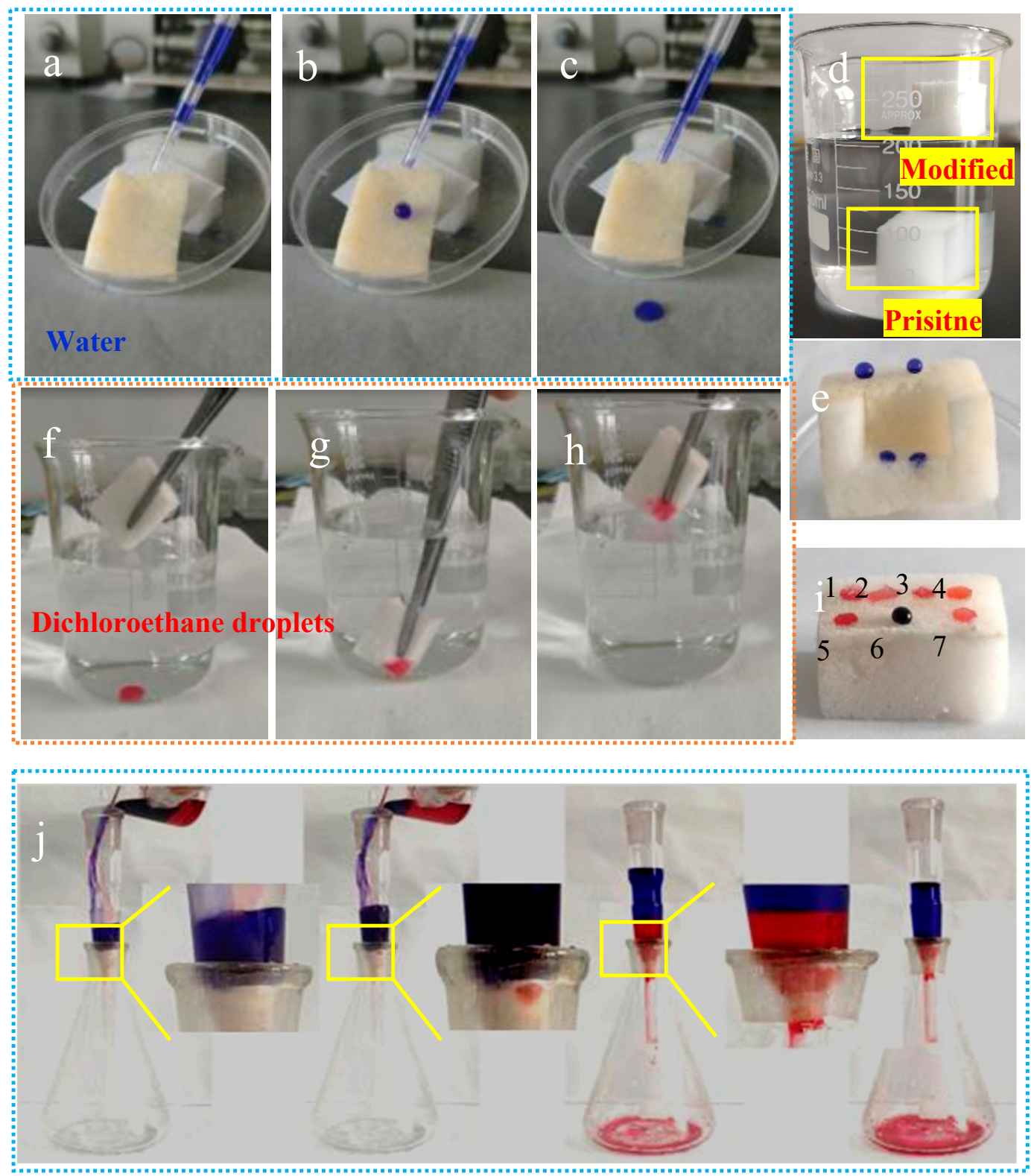

Figure 5. Rolling photos of water droplets on modified melamine sponges $(\mathbf{a}-\mathbf{c})$, the state of melamine sponges in water (d), wettability of modified and unmodified melamine sponge (e), dichloroethane droplets absorption (f-h), absorption of different kinds of oil/organic solvent (1. toluene, 2. silicone oil, 3. gasoline, 4. diesel oil, 5 . corn oil, 6 . water, and 7. petroleum ether) by modified melamine sponge (i) and separation of an oil/water mixture via modified melamine sponges (j). 
Figure 6 is a qualitative measurement of the absorption capacity of a modified melamine sponge for oil/organic solvent. As shown in Figure 6a, the modified sponge exhibits excellent absorption capacity towards a wide range of organic solvents and oils, even in the case of high-density solvents (such as dichloromethane) and viscous oils (such as corn oil and silicone oil) can be easily recycled by gently squeezing. The modified sponges can absorb 60-150 times its dry weight in the above solvents and oils. The weight ratio of absorbed solvent/sponges not only depends on the density and viscosity of the oils/organic solvents, but also may be related to the swelling of polymers in some solvents. The excellent oil/water separation ability is further confirmed by the reusability of modified sponges for different oil/organic solvent. The melamine sponge will be subjected to repeated stress extrusion and porous structure collapse; thus, absorption capacity will be reduced. Figure S4 shows the destruction of the melamine sponge skeleton after multiple extrusion. However, the modified sponges still keep a strong absorption capacity after 10 absorption-desorption cycled times (Figure 6b-e). Figure 6f shows the water contact angle of the modified sponge after absorbing and extruding different oils/organic solvent for 10 and 40 cycles. As shown in Figure $6 f$, the water contact angle of the modified sponge changes little after repeatedly absorbing and extruding different oils/organic solvent, and still displays the super-hydrophobic characteristics. These results indicate that the facile construction of modified sponge with special wettability has a broad application prospect in multi-purpose cycle absorption of oil/organic solvent and has great practical application potential. The excellent oil absorption and recycling property of modified sponges result from the chemical modification of surface hydrophobicity and the construction of micro-nanoscale hierarchical structures on the sponge surface, which is very important for the final super-hydrophobicity, just like the surface of the lotus leaf (Figure S5). Combining roughness on both the micro- and nanoscale results in a hierarchically structured surface, which is the basis of the Lotus effect. The lowest area of contact between the droplet and the surface occurs in the case of the hierarchical structure, which can be expected to have super-hydrophobicity. In addition, the multiscale roughness allows for more stable air pocket formation, guarding against destabilizing factors on both the micro and nanoscale.
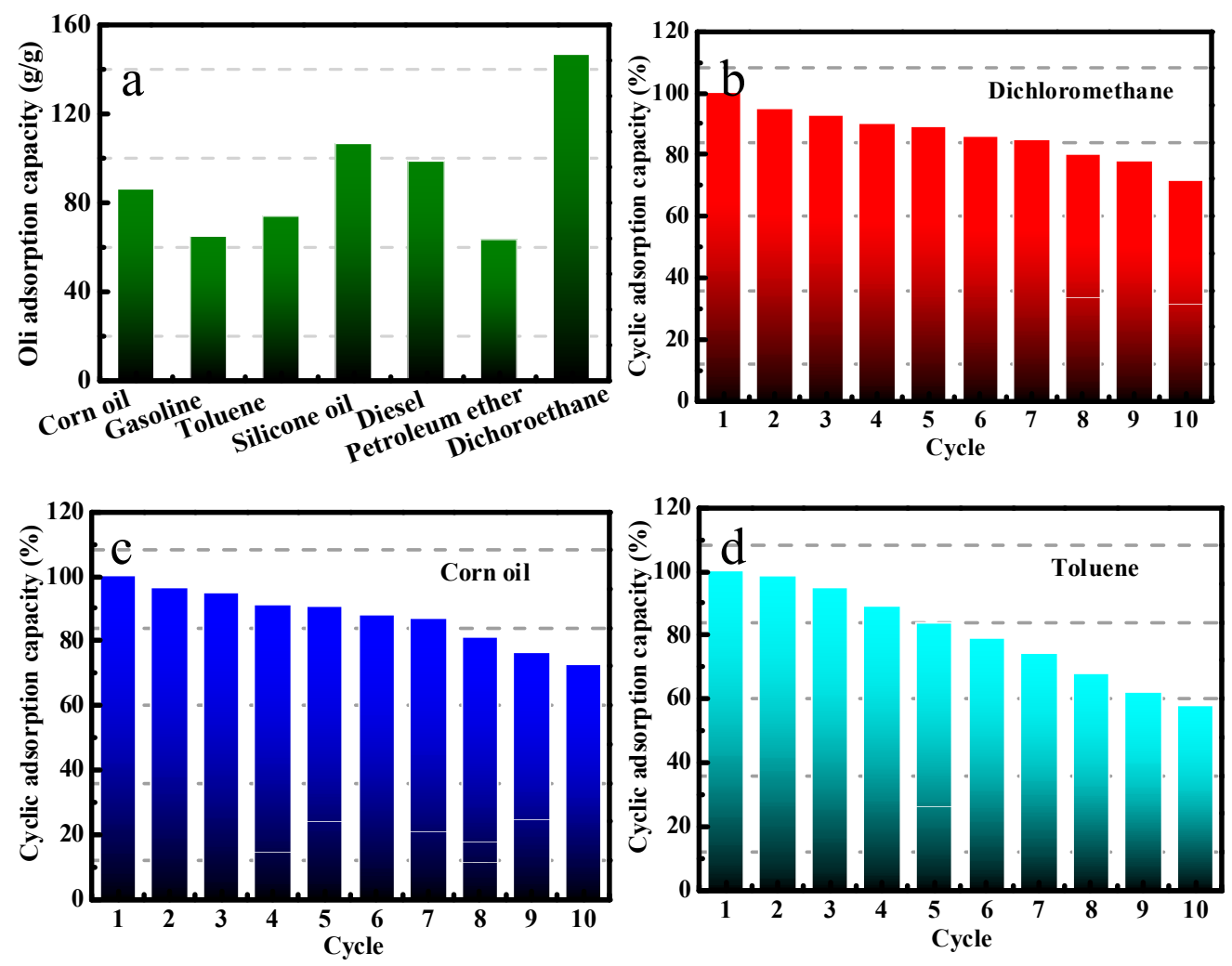

Figure 6. Cont. 

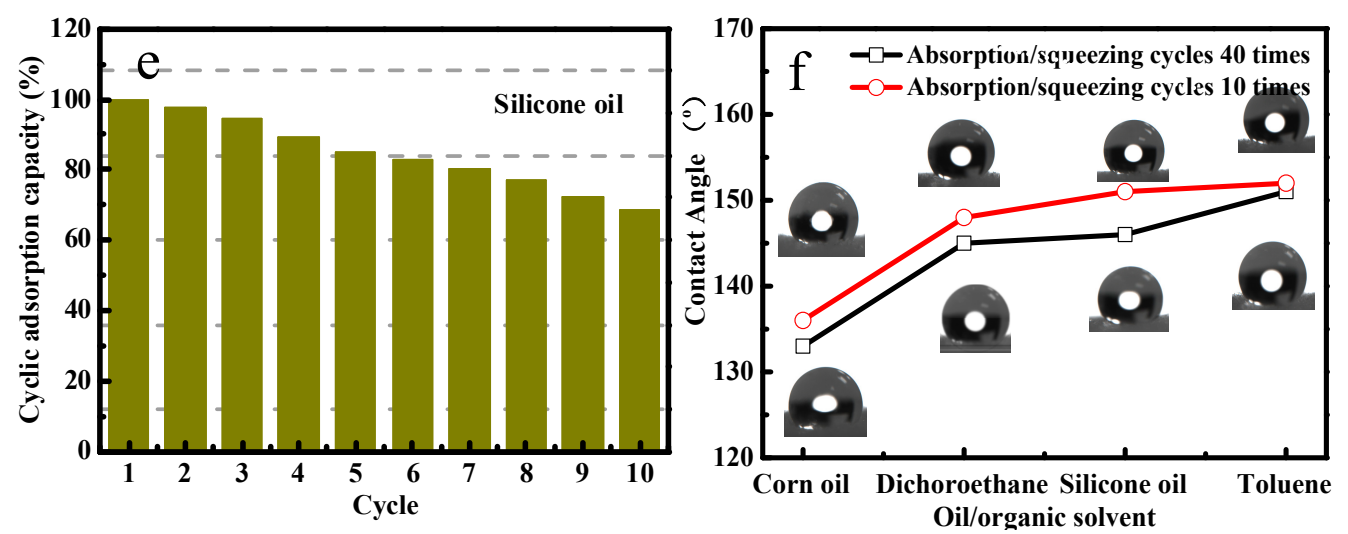

Figure 6. The absorption capacity (a) and cyclic serviceability (b-e) of the super-hydrophobic melamine sponge for various types of oils and organic solvents; (f) the water contact angle of the modified sponge after absorbing and extruding different oil/organic solvent for 10 and 40 cycles.

\section{Conclusions}

In conclusion, a versatile, facile, green, and low-cost surface assembly strategy was designed based on plant-inspired chemistry to prepare super-hydrophobic surfaces. The micro/nano hierarchical roughness structure was first obtained by fabricating micro-nano phytic acid metal complexes' aggregations, and then the super-hydrophobicity surface will be achieved by grafting thiol-containing hydrophobic groups on the above rough surface by a metal-thiol coordination effect. This facile method can be employed to prepare various super-hydrophobic materials. Furthermore, taking the PA-Fe (III)-HT coated melamine sponges as an example, the super-hydrophobic melamine sponges can be successfully used to collect oil spills and display excellent separation efficiency.

Supplementary Materials: The following are available online at http://www.mdpi.com/2073-4360/11/12/2047/s1, Figure S1: The initial image before mapping, Figure S2: The XPS wide-scan spectrum of modified melamine sponge, Figure S3: The SEM image of the PA-Fe complex deposit, Figure S4: SEM images: a. unsqueezed melamine sponge, b. squeezed melamine sponge (10 cycles) and c. squeezed melamine sponge (40 cycles), Figure S5: Schematic of the hydrophobic model inspired by the surface of lotus leaves, Movie S1: The water droplets rolled from the surface of the modified melamine sponge, Movie S2: The dichloroethane droplets absorption of the modified melamine sponge, Movie S3: The separation of an oil/water mixture via modified melamine sponges.

Author Contributions: Conceptualization, Y.W.; Methodology, L.D., and J.X.; Investigation, H.L., and M.Z.; Funding Acquisition, L.D., P.Z., and H.M.; Writing-Review and Editing, L.D., and J.X.

Funding: The project is supported by the Nantong Science and Technology Program (JC2018104, MS12017018-4, XA2017004), Innovation and Entrepreneurship training Project for College students in Jiangsu Province (201910304166T, 201910304134H), the National Natural Science Foundation of China $(61571245,21375067)$, and the National Key R \& D Plan (2016YFB0303102).

Conflicts of Interest: The authors declare no conflicts of interest.

\section{References}

1. Ge, J.; Shi, L.-A.; Wang, Y.-C.; Zhao, H.-Y.; Yao, H.-B.; Zhu, Y.-B.; Zhang, Y.; Zhu, H.-W.; Wu, H.-A.; Yu, S.-H. Joule-heated graphene-wrapped sponge enables fast clean-up of viscous crude-oil spill. Nat. Nanotechnol. 2017, 12, 434. [CrossRef] [PubMed]

2. Ge, J.; Zhao, H.-Y.; Zhu, H.-W.; Huang, J.; Shi, L.-A.; Yu, S.-H. Advanced Sorbents for Oil-Spill Cleanup: Recent Advances and Future Perspectives. Adv. Mater. 2016, 28, 10459-10490. [CrossRef] [PubMed]

3. Doshi, B.; Sillanpää, M.; Kalliola, S. A review of bio-based materials for oil spill treatment. Water Res. 2018, 135, 262-277. [CrossRef] [PubMed]

4. Dombrowski, N.; Donaho, J.A.; Gutierrez, T.; Seitz, K.W.; Teske, A.P.; Baker, B.J. Reconstructing metabolic pathways of hydrocarbon-degrading bacteria from the Deepwater Horizon oil spill. Nat. Microbiol. 2016, 1, 16057. [CrossRef] 
5. Kwok Richard, K.; Engel Lawrence, S.; Miller Aubrey, K.; Blair, A.; Curry Matthew, D.; Jackson, W.B.; Stewart Patricia, A.; Stenzel Mark, R.; Birnbaum Linda, S.; Sandler Dale, P.; et al. The GuLF STUDY: A Prospective Study of Persons Involved in the Deepwater Horizon Oil Spill Response and Clean-Up. Environ. Health Perspect. 2017, 125, 570-578. [CrossRef]

6. Sergy, G.A.; Guénette, C.C.; Owens, E.H.; Prince, R.C.; Lee, K. In-situ Treatment of Oiled Sediment Shorelines. Spill Sci. Technol. Bull. 2003, 8, 237-244. [CrossRef]

7. Fragouli, D.; Athanassiou, A. Graphene heaters absorb faster. Nat. Nanotechnol. 2017, 12, 406. [CrossRef]

8. Chu, Z.; Feng, Y.; Seeger, S. Oil/Water Separation with Selective Superantiwetting/Superwetting Surface Materials. Angew. Chem. Int. Ed. 2015, 54, 2328-2338. [CrossRef]

9. Gao, X.; Zhou, J.; Du, R.; Xie, Z.; Deng, S.; Liu, R.; Liu, Z.; Zhang, J. Robust Superhydrophobic Foam: A Graphdiyne-Based Hierarchical Architecture for Oil/Water Separation. Adv. Mater. 2016, 28, 168-173. [CrossRef]

10. Zhou, J.; Sun, Z.; Chen, M.; Wang, J.; Qiao, W.; Long, D.; Ling, L. Macroscopic and Mechanically Robust Hollow Carbon Spheres with Superior Oil Adsorption and Light-to-Heat Evaporation Properties. Adv. Funct. Mater. 2016, 26, 5368-5375. [CrossRef]

11. Wang, J.; Shang, L.; Cheng, Y.; Ding, H.; Zhao, Y.; Gu, Z. Microfluidic Generation of Porous Particles Encapsulating Spongy Graphene for Oil Absorption. Small 2015, 11, 3890-3895. [CrossRef] [PubMed]

12. Ma, Q.; Cheng, H.; Fane, A.G.; Wang, R.; Zhang, H. Recent Development of Advanced Materials with Special Wettability for Selective Oil/Water Separation. Small 2016, 12, 2186-2202. [CrossRef] [PubMed]

13. Padaki, M.; Surya Murali, R.; Abdullah, M.S.; Misdan, N.; Moslehyani, A.; Kassim, M.A.; Hilal, N.; Ismail, A.F. Membrane technology enhancement in oil-water separation. A review. Desalination 2015, 357, 197-207. [CrossRef]

14. Liu, Y.; Su, Y.; Guan, J.; Cao, J.; Zhang, R.; He, M.; Gao, K.; Zhou, L.; Jiang, Z. 2D Heterostructure Membranes with Sunlight-Driven Self-Cleaning Ability for Highly Efficient Oil-Water Separation. Adv. Funct. Mater. 2018, 28, 1706545. [CrossRef]

15. Ding, L.; Gao, J.; Chung, T.-S. Schiff base reaction assisted one-step self-assembly method for efficient gravity-driven oil-water emulsion separation. Sep. Purif. Technol. 2019, 213, 437-446. [CrossRef]

16. Ding, L.; Wang, Y.; Zhu, P.; Bai, Y. One-step plant-inspired reaction that transform membrane hydrophobicity into high hydrophilicity and underwater super oleophobicity for oil-in-water emulsion separation. Appl. Surf. Sci. 2019, 479, 423-429. [CrossRef]

17. Wang, Y.; Zhu, Y.; Yang, C.; Liu, J.; Jiang, W.; Liang, B. Facile Two-Step Strategy for the Construction of a Mechanically Stable Three-Dimensional Superhydrophobic Structure for Continuous Oil-Water Separation. ACS Appl. Mater. Interfaces 2018, 10, 24149-24156. [CrossRef]

18. Qiang, F.; Hu, L.-L.; Gong, L.-X.; Zhao, L.; Li, S.-N.; Tang, L.-C. Facile synthesis of super-hydrophobic, electrically conductive and mechanically flexible functionalized graphene nanoribbon/polyurethane sponge for efficient oil/water separation at static and dynamic states. Chem. Eng. J. 2018, 334, 2154-2166. [CrossRef]

19. Mi, H.-Y.; Jing, X.; Xie, H.; Huang, H.-X.; Turng, L.-S. Magnetically driven superhydrophobic silica sponge decorated with hierarchical cobalt nanoparticles for selective oil absorption and oil/water separation. Chem. Eng. J. 2018, 337, 541-551. [CrossRef]

20. Yang, Y.; Li, X.; Zheng, X.; Chen, Z.; Zhou, Q.; Chen, Y. 3D-Printed Biomimetic Super-Hydrophobic Structure for Microdroplet Manipulation and Oil/Water Separation. Adv. Mater. 2018, 30, 1704912. [CrossRef]

21. Liu, H.; Kang, Y. Superhydrophobic and superoleophilic modified EPDM foam rubber fabricated by a facile approach for oil/water separation. Appl. Surf. Sci. 2018, 451, 223-231. [CrossRef]

22. Saththasivam, J.; Yiming, W.; Wang, K.; Jin, J.; Liu, Z. A Novel Architecture for Carbon Nanotube Membranes towards Fast and Efficient Oil/water Separation. Sci. Rep. 2018, 8, 7418. [CrossRef] [PubMed]

23. Dashairya, L.; Rout, M.; Saha, P. Reduced graphene oxide-coated cotton as an efficient absorbent in oil-water separation. Adv. Compos. Hybrid Mater. 2018, 1, 135-148. [CrossRef]

24. Lei, Z.; Zhang, G.; Deng, Y.; Wang, C. Thermoresponsive Melamine Sponges with Switchable Wettability by Interface-Initiated Atom Transfer Radical Polymerization for Oil/Water Separation. ACS Appl. Mater. Interfaces 2017, 9, 8967-8974. [CrossRef]

25. Guan, Y.; Cheng, F.; Pan, Z. Superwetting Polymeric Three Dimensional (3D) Porous Materials for Oil/Water Separation: A Review. Polymers 2019, 11, 806. [CrossRef] 
26. Pinto, J.; Athanassiou, A.; Fragouli, D. Surface modification of polymeric foams for oil spills remediation. J. Environ. Manag. 2018, 206, 872-889. [CrossRef]

27. Lei, Z.; Deng, Y.; Wang, C. Multiphase surface growth of hydrophobic ZIF-8 on melamine sponge for excellent oil/water separation and effective catalysis in a Knoevenagel reaction. J. Mater. Chem. A 2018, 6, 3258-3263. [CrossRef]

28. Chen, X.; Weibel, J.A.; Garimella, S.V. Continuous Oil-Water Separation Using PolydimethylsiloxaneFunctionalized Melamine Sponge. Ind. Eng. Chem. Res. 2016, 55, 3596-3602. [CrossRef]

29. Qiu, S.; Jiang, B.; Zheng, X.; Zheng, J.; Zhu, C.; Wu, M. Hydrophobic and fire-resistant carbon monolith from melamine sponge: A recyclable sorbent for oil-water separation. Carbon 2015, 84, 551-559. [CrossRef]

30. Wang, C.-F.; Huang, H.-C.; Chen, L.-T. Protonated Melamine Sponge for Effective Oil/Water Separation. Sci. Rep. 2015, 5, 14294. [CrossRef]

31. Yilgör, E.; Söz, C.K.; Yilgör, I. Wetting behavior of superhydrophobic poly(methyl methacrylate). Prog. Org. Coat. 2018, 125, 530-536. [CrossRef]

32. Jiaqiang, E.; Jin, Y.; Deng, Y.; Wei, Z.; Zhao, X.; Han, D.; Peng, Q.; Zhang, Z. Wetting Models and Working Mechanisms of Typical Surfaces Existing in Nature and Their Application on Superhydrophobic Surfaces: A Review. Adv. Mater. Interfaces 2018, 5, 1701052-1701091. [CrossRef]

33. Zulfiqar, U.; Hussain, S.Z.; Subhani, T.; Hussain, I. Mechanically robust superhydrophobic coating from sawdust particles and carbon soot for oil/water separation. Colloids Surf. A 2018, 539, 391-398. [CrossRef]

34. Li, H.; Liang, T.; Lai, X.; Su, X.; Zhang, L.; Zeng, X. Vapor-liquid interfacial reaction to fabricate superhydrophilic and underwater superoleophobic thiol-ene/silica hybrid decorated fabric for oil/water separation. Appl. Surf. Sci. 2018, 427, 92-101. [CrossRef]

35. Li, F.; Wang, Z.; Huang, S.; Pan, Y.; Zhao, X. Flexible, Durable, and Unconditioned Superoleophobic/ Superhydrophilic Surfaces for Controllable Transport and Oil-Water Separation. Adv. Funct. Mater. 2018, 28, 1706867. [CrossRef]

36. Wang, Z.; Yang, H.-C.; He, F.; Peng, S.; Li, Y.; Shao, L.; Darling, S.B. Mussel-Inspired Surface Engineering for Water-Remediation Materials. Matter 2019, 1, 115-155. [CrossRef]

37. Fang, Y.; Gonuguntla, S.; Soh, S. Universal Nature-Inspired Coatings for Preparing Noncharging Surfaces. ACS Appl. Mater. Interfaces 2017, 9, 32220-32226. [CrossRef]

38. Yang, Z.; Qiu, H.; Li, X.; Gao, P.; Huang, N. Plant-inspired gallolamine catalytic surface chemistry for engineering an efficient nitric oxide generating coating. Acta Biomater. 2018, 76, 89-98. [CrossRef]

39. Gan, D.; Xing, W.; Jiang, L.; Fang, J.; Zhao, C.; Ren, F.; Fang, L.; Wang, K.; Lu, X. Plant-inspired adhesive and tough hydrogel based on Ag-Lignin nanoparticles-triggered dynamic redox catechol chemistry. Nat. Commun. 2019, 10, 1487. [CrossRef]

40. Dong, L.; Gao, Z.A.; Lin, N. Self-assembly of metal-organic coordination structures on surfaces. Prog. Surf. Sci. 2016, 91, 101-135. [CrossRef]

41. Wang, X.; Jiang, Z.; Shi, J.; Liang, Y.; Zhang, C.; Wu, H. Metal-Organic Coordination-Enabled Layer-by-Layer Self-Assembly to Prepare Hybrid Microcapsules for Efficient Enzyme Immobilization. ACS Appl. Mater. Interfaces 2012, 4, 3476-3483. [CrossRef] [PubMed]

42. Altman, M.; Shukla, A.D.; Zubkov, T.; Evmenenko, G.; Dutta, P.; van der Boom, M.E. Controlling Structure from the Bottom-Up: Structural and Optical Properties of Layer-by-Layer Assembled Palladium Coordination-Based Multilayers. J. Am. Chem. Soc. 2006, 128, 7374-7382. [CrossRef] [PubMed]

43. Liu, Y.; Zhang, K.; Son, Y.; Zhang, W.; Spindler, L.M.; Han, Z.; Ren, L. A smart switchable bioinspired copper foam responding to different $\mathrm{pH}$ droplets for reversible oil-water separation. J. Mater. Chem. A 2017, 5, 2603-2612. [CrossRef]

44. Li, L.; Zhang, G.; Su, Z. One-Step Assembly of Phytic Acid Metal Complexes for Superhydrophilic Coatings. Angew. Chem. Int. Ed. 2016, 55, 9093-9096. [CrossRef] [PubMed]

(C) 2019 by the authors. Licensee MDPI, Basel, Switzerland. This article is an open access article distributed under the terms and conditions of the Creative Commons Attribution (CC BY) license (http://creativecommons.org/licenses/by/4.0/). 